\title{
HARDNESS OF TOOL STEEL 55NiCrMoV7 AFTER FOUR DIFFERENT TREATMENT TYPES
}

\author{
${ }^{1}$ Eva MAZANCOVÁ, ${ }^{2}$ Pavel KUČERA, ${ }^{3}$ Michal ŠOFER \\ ${ }^{1}$ VSB - Technical University of Ostrava, Faculty of Materials Science and Technology, Ostrava, Czech \\ Republic, EU, eva.mazancova@vsb.cz \\ 2Vitkovice Cylinders a.s., Ostrava, Czech Republic, EU, pavel.kucera@vitkovice.cz \\ ${ }^{3}$ VSB - Technical University of Ostrava, Faculty of Mechanical Engineering, Ostrava, Czech Republic, EU, \\ michal.sofer@vsb.cz
}

https://doi.org/10.37904/metal.2019.833

\begin{abstract}
Work is aimed at tool steel of $55 \mathrm{NiCrMoV7}$ after four different heat treatment types. One part of material was after nitridation, other was quenched using laser, the third part was quenched by laser and subsequently nitrided and one part of steel $55 \mathrm{NiCrMoV} 7$ was in basic state after conventional quenching and tempering. Results of surface hardening using micro-hardness of all heat treated modes were compared mutually to find the most effective heat treatment. Micro-hardness was investigated from surface into the $2 \mathrm{~mm}$ depth of material. Micro-structure investigation completes the study and includes both purity evaluation and structure using light and SEM microscopy. The given steel type is suitable material for different applications, e.g. for cutting tools.
\end{abstract}

Keywords: Steel 55NiCrMoV7, nitridation, laser quenching, micro-hardness, microstructure

\section{INTRODUCTION}

Tool steel 19663 belongs among alloyed steels and is predetermined for higher temperature applications $[1,2]$. It is characterised by favourable level of toughness. Given steel is low alloyed one on the basis of $\mathrm{Cr}-\mathrm{Ni}-\mathrm{Mo}-\mathrm{V}$, which shows, thanks the lower carbon content and higher Ni level, better impact resistance unlike higher, alloyed steels, however at the expense of its wear resistance [3,4]. Properties of mentioned steel and thereby its working use are dependent on chemical composition, respectively on portion of alloying elements and also its treatment type [5]. Steel $55 \mathrm{NiCrMoV} 7$ is suitable for applications where favourable ratio of strength and toughness is demanded. Here can be mentioned tools production for extrusion, for knifes, snips and for dies with high lifetime $[6,7]$. Conventionally, the steel is annealed, quenched and tempered $[2,6,7]$. At present demands on higher level of tool steels lifetime at higher hardness of surface and under-surface zones are impulses for searching new possibilities of surface treatment, e.g. nitridation, laser quenching, plasma treatment and/or some combinations of mentioned techniques. These surface treatments lead to surface and under-surface hardness increase at preservation of basic material toughness $[1,2,5,8]$.

The aim of presented paper is to show changes in micro-hardness of the tool steel 55NiCrMoV7 after different treatment modes and to reveal the most optimised heat treatment mode.

\section{EXPERIMENTAL}

For study four knifes from one tool steel of $55 \mathrm{NiCrMoV} 7$ were used. Subsequently, one knife was heat treated conventionally (basic material marked with $\mathrm{BM}$ ) and the others were investigated after surface treatment by nitridation (represents the $\mathrm{N}$ ), other after laser quenching (LQ) and the last one was after laser quenching and final nitridation (in text marked with $L Q+N$ ). Nitridations as well as $L Q$ were applied under the same conditions. Chemical composition corresponded to (in wt \%): $0.5 \mathrm{C}, 0.3 \mathrm{Si}, 0.8 \mathrm{Mn}, 1 \mathrm{Cr}, 0.4 \mathrm{Mo}, 1.6 \mathrm{Ni}, 0.1 \mathrm{~V}$. Basic material was studied from point of view of purity according the ČSN ISO 4967 by use of microscope OLYMPUS IX 70. 
In case of all knifes micro-hardness evaluation (HV0.2 in accord with the CSN EN ISO 6507-1) was carried out from surface into the $2 \mathrm{~mm}$ central material depth (20 indents) by LECO 2000 [8\}. Microstructure was investigated by use of SEM JEOL JSM-6490 LV equipped with EDA.

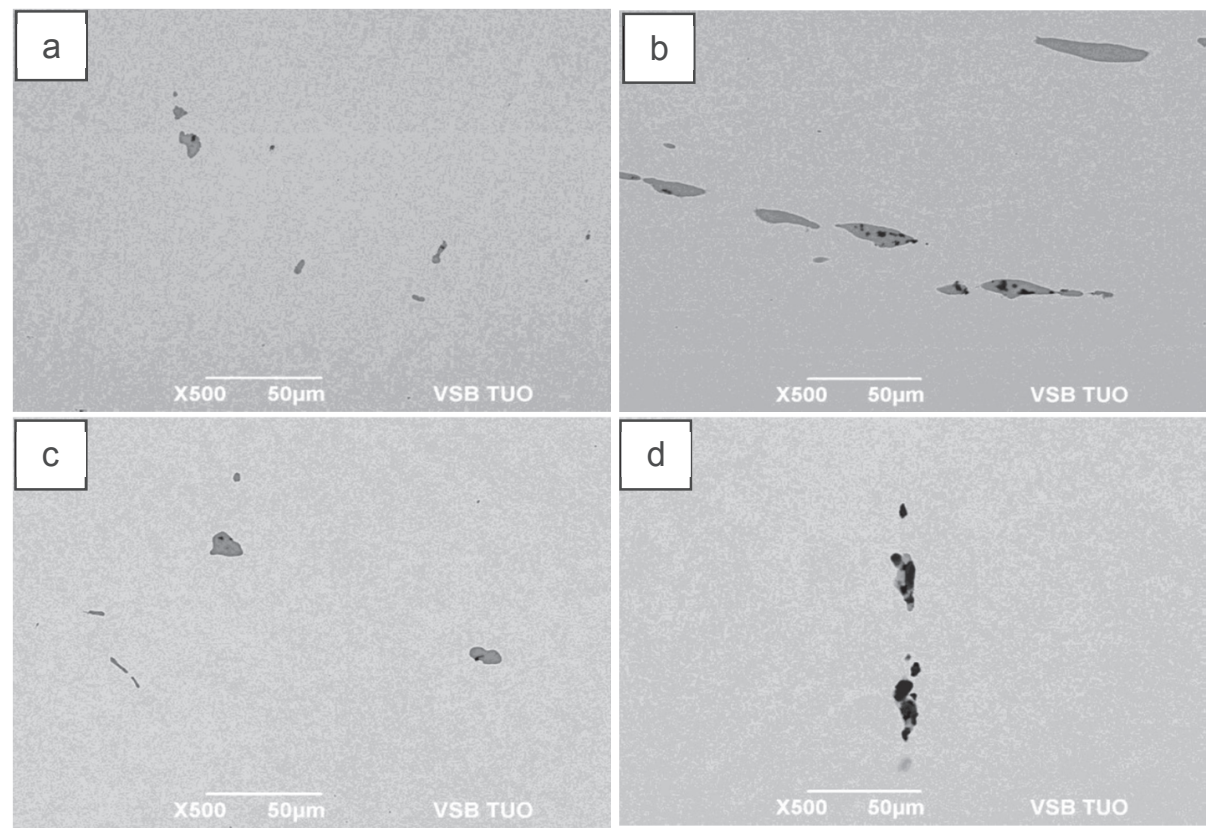

Figure 1 Maximal observed inclusions in studied basic material BM (a), N (b), LQ (c) and LQ+N (d)

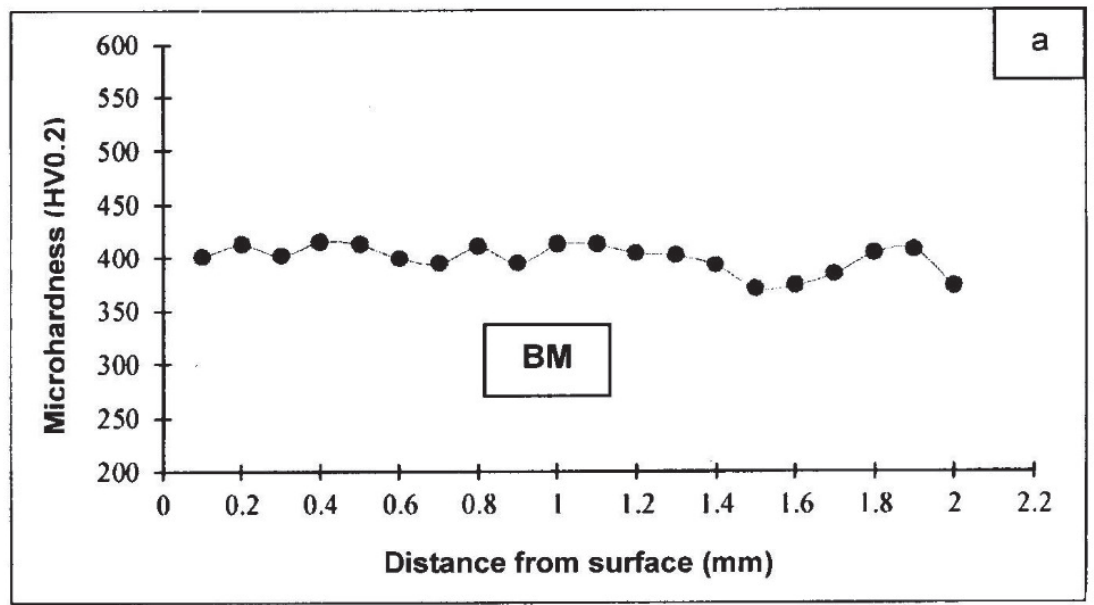

Figure 2a Micro-hardness in dependence on distance from surface for basic material (BM)

\section{RESULTS AND THEIR ANEALYSIS}

Impurities detected in studied material corresponded to grade A1 (material BM, LQ) and to A1.5 (material N, $L Q+N$ ) and that was point either of oxides or oxides-sulfitic complex on the basis of $\mathrm{Al}, \mathrm{Mn}$, eventually with $\mathrm{Mg}$ (BM) and/or Ca (LQ). Figure 1 represents examples of the most intensive impurities found in all four studied heat treated variants. In tool steels, presence of non-metallic inclusions is standard [1], however their minimization is desirable, because those degrade material properties e.g. fatigue and impact resistance. Elongated inclusions represent localized tension concentrates on the inclusion tips, support anisotropy of mechanical properties in transverse direction and that phenomena can be raised to a power by segregation, which also was detected in case of BM [9]. 

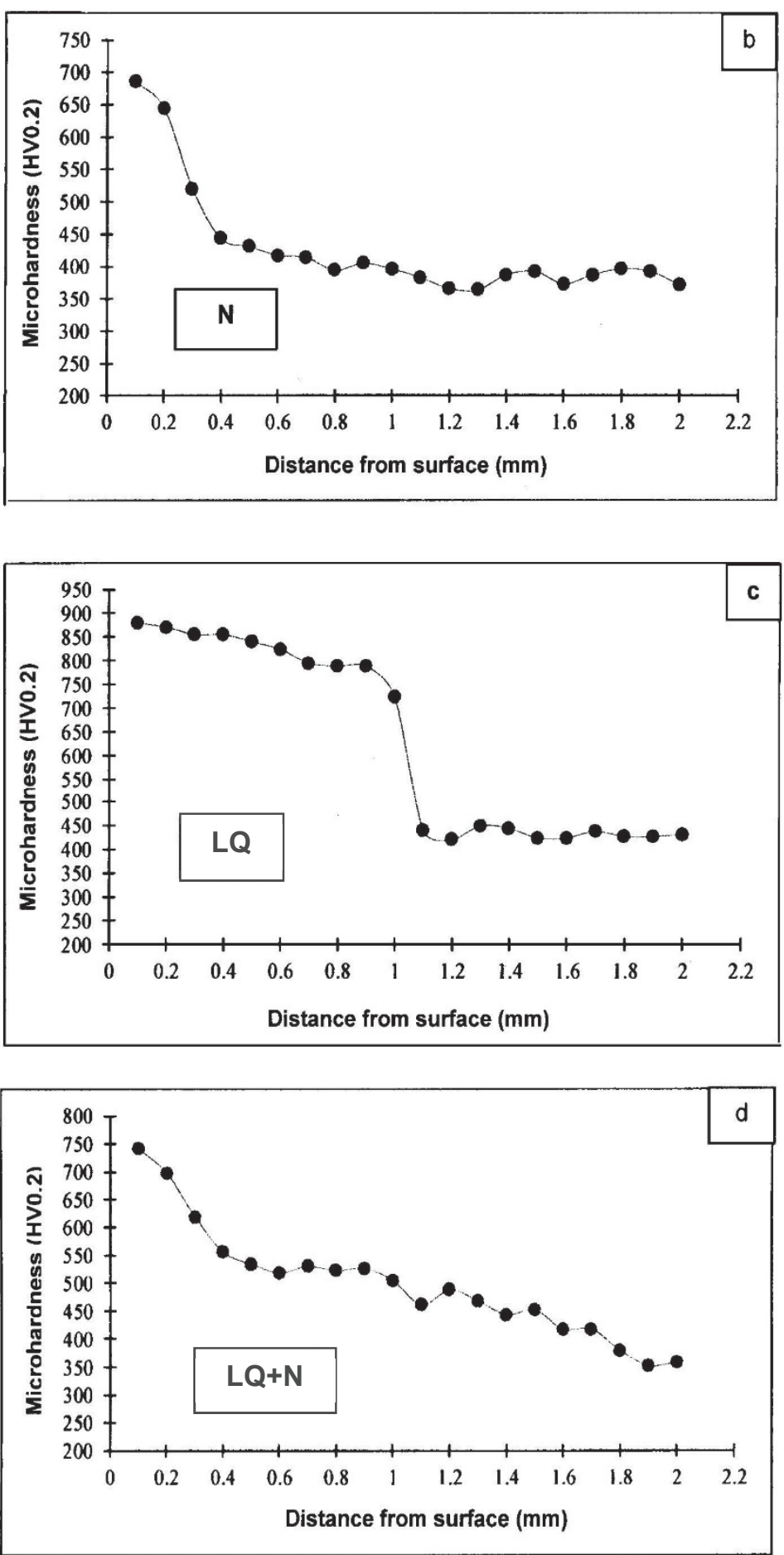

Figure 2b-c Micro-hardness in dependence on distance from surface for N (b), LQ (c), LQ+N (d)

Micro-hardness results from surface up to $2 \mathrm{~mm}$ depth represent Figures 2a-2d. Micro-hardness of the BM shows stationary shape of curve being on the level of 399HV0.2 with selective standard deviation of 14.06 see Figure 2a. After nitridation $(\mathrm{N})$, surface revealed maximal micro-hardness of $686 \mathrm{HV} 0.2,0.2 \mathrm{~mm}$ under surface it was $644 \mathrm{HV} 0.2$ yet, however afterwards micro-hardness fall was registered up to $443 \mathrm{HV} 0.2$ in distance of 0.4 $\mathrm{mm}$ away surface. Between 0.5-2 mm average micro-hardness of 392HV0.2 with standard deviation of 18.67 
was detected as it Figure $\mathbf{2 b}$ represents. It is known, to gain hard nitride layer with different demanded properties as e.g. favorable fatigue with high strength level, is difficult, especially from point of diffusion [10].

After LQ studied steel reached the highest level of micro-hardness on the surface (8820HV0.2) and up to $1 \mathrm{~mm}$ under surface only $18 \%$ decrease on $725 \mathrm{HV} 0.2$ was detected - see Figure $2 \mathrm{c}$. Between 1.1-2 mm drop of steel micro-hardness followed and next stagnation of medium level of $432 \mathrm{HV} 0.2$ with selective standard deviation of 9.87 was achieved as it from Figure 2c follows. Micro-hardness of steel after LQ+N showed $740 \mathrm{HV} 0.2$ on the surface with next decrease up to 534HV0.2 (0.4 mm under surface), afterwards short stabilization followed (516HV0.2 with standard deviation of 15.42) and other decrease up to $2 \mathrm{~mm}$ (342 HV0.2) was registered - see Figure $\mathbf{2 d}$. In depth of $2 \mathrm{~mm}$, all materials, including the BM one, showed close levels of micro-hardness being in accord with [11, 12]. From point of micro-hardness, the steel 19663 shows the best results after laser quenching (LQ).

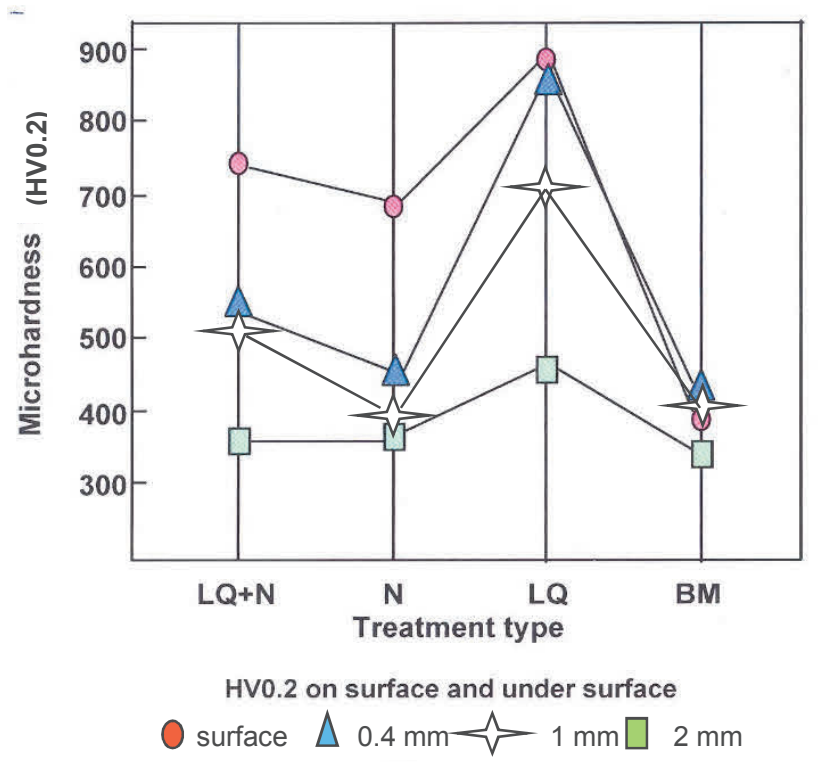

Figure 3 Micro-hardness in dependence on treatment type on the surface, $0.4 \mathrm{~mm} 1 \mathrm{~mm}$ and $2 \mathrm{~mm}$ under surface

Figure 3 summarizes micro-hardness results of all investigated heat treatment variants on the surface, $0.4 \mathrm{~mm}, 1 \mathrm{~mm}$ and $2 \mathrm{~mm}$ under surface. From this figure it is quite clear seen, that material of tool steel 19663 after laser quenching shows the best hardness parameters, even deeper in material, unlike other heat treated variants and after application of followed nitriding those are kept down. Maximal level of micro-hardness can be associated with microstructure of $L Q$ material, revealing extremely fine martensite (reaching $1 \mathrm{~mm}$ depth practically) with ultra-fine precipitates being finer than the nitride particles in material after LQ with subsequent nitridation. Deeper than $1 \mathrm{~mm}$, the primary martensite microstructure has become slightly coarser. This finding is also in accord with works [13-15]. Microstructure images (SEM) after all investigated heat treatment types on the surface, in depth of $1 \mathrm{~mm}$ and $2 \mathrm{~mm}$ under surface can be seen in Figure 4. Regarding microstructure of only nitrided sample, this one showed under nitride layer of 2.3-4 $\mu \mathrm{m}$ in thickness the coarsest microstructure as it from Figures $\mathbf{4 a}, \mathbf{d}, \mathbf{g}$, j comparison follows, respectively from Figures $\mathbf{4 b}, \mathbf{c}, \mathbf{e}, \mathbf{f}, \mathbf{h}, \mathbf{i}, \mathbf{k}, \mathbf{l}$, even when Figures $4 \mathrm{e}, \mathrm{f}$ demonstrate smaller magnifications. Mentioned fall of micro-hardness after nitridation of $L Q$ surface could be elucidated by consequence of heating and grain coarsening in martensite area of extremely fine microstructure formed after LQ operation on the surface and under surface. It can be supposed, nitrided layer after LQ was not able to compensate micro-hardness level in original ultra-fine martensitic layer formed 
after laser exposition and that could be reason of found HV0.2 degradation. Mentioned degradation can be also seen from differences comparison between Figures $\mathbf{4 g}$-i and $\mathbf{4 j - 1}$.
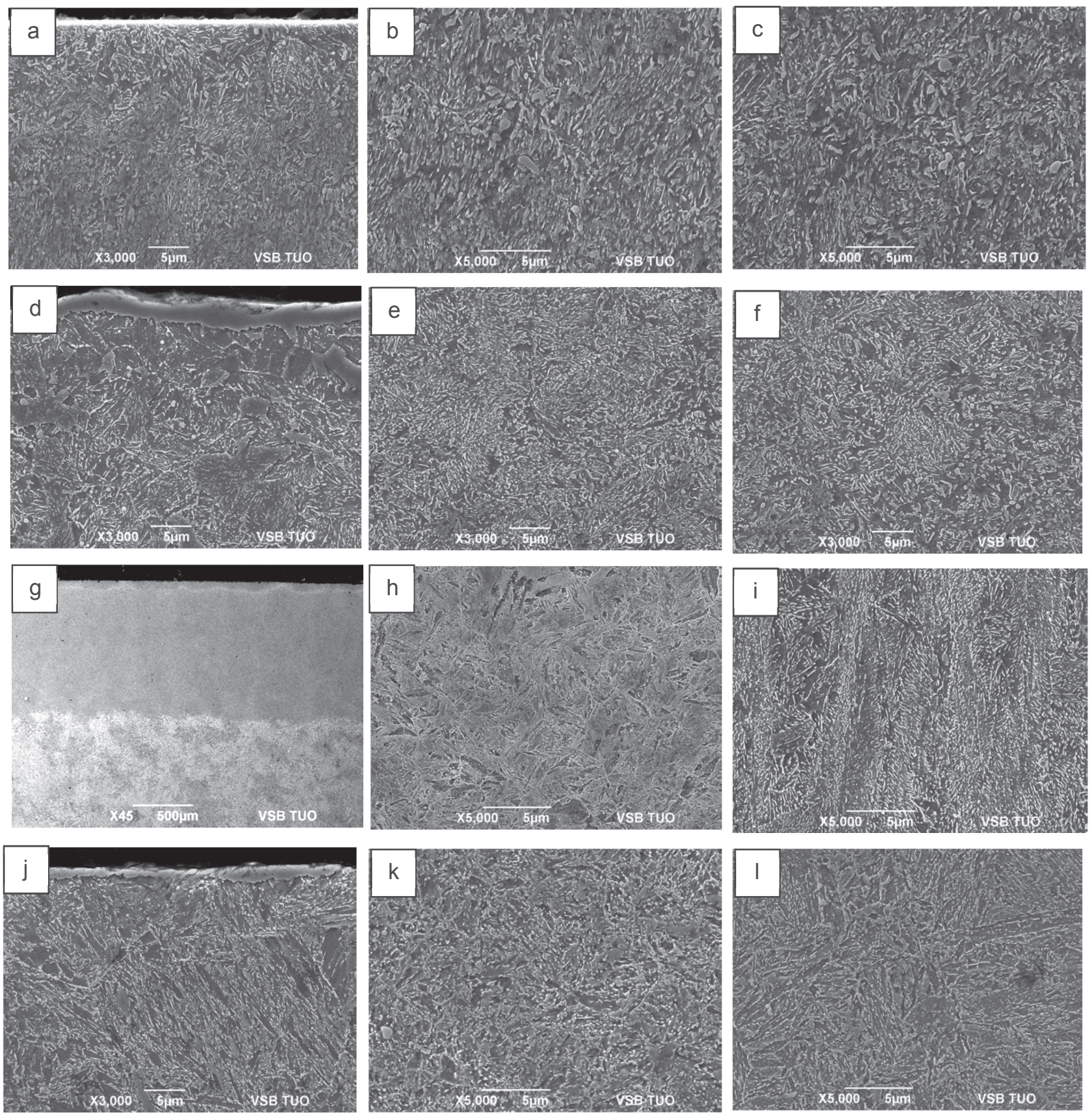

Figure 4 Microstructure image of all heat treated steel types directly under surface (left figures), $1 \mathrm{~mm}$ under surface (median figures), $2 \mathrm{~mm}$ under surface (right figures); BM (a-c), N (d-f), LQ (g-i), LQ+N (j-l)

\section{CONCLUSION}

Four types of surface treatment of tool steel $55 \mathrm{NiCrMoV} 7$ were applied. The basic material (BM) was treated conventionally, other was nitrided $(\mathrm{N})$, one was quenched by laser (LQ) and the last was after $L Q$ nitrided $(L Q+N)$ to find out which treatment type will be from point of hardness the best. Investigation revealed in all 
cases mostly complex oxid-sulfitic inclusions on basis of $\mathrm{Al}, \mathrm{Mn}$, eventually with $\mathrm{Mg}$ (case of $\mathrm{BM}$ ) and/or $\mathrm{Ca}$ (case of $L Q$ ).

The LQ material showed the highest level of micro-hardness (8820HV0.2) and up to $1 \mathrm{~mm}$ under surface was $18 \%$ decrease recorded only. Between 1.1-2 mm, drop of steel micro-hardness followed and next stagnation on medium level of $432 \mathrm{HV} 0.2$ was detected. In this case martensite microstructure was also the finest in comparison with other three treatment variants. As the second best treatment LQ+N showed, however $0.4 \mathrm{~mm}$ under surface a $35 \%$ fall of micro-hardness was already observed, while in case of sample $\mathrm{N}$ it was $47 \%$. Basic material being conventionally treated revealed or else more balanced micro-hardness between surface and $2 \mathrm{~mm}$ depth, but not higher than 420HV0.2.

Observed decrease in micro-hardness after $L Q+N$ in comparison to $L Q$ sample can be elucidated by partial grain coarsening after reheating on nitridation temperature when nitrided surface was not able to compensate micro-hardness level in primary ultra-fine martensitic microstructure.

\section{ACKNOWLEDGEMENTS}

This paper was created in cooperation with company of VÍTKOVICE CYLINDERS Inc. and at the FMT within the project No. SP2019/43 Specific research in metallurgical, material and procedural engineering.

\section{REFERENCES}

[1] ROBERTS, G. A., KRAUSS, G. and KENNEDY, R. Tool Steels. 5th ed. Materials Park: ASM International, 1998. p. 364.

[2] CALLISTER, W.D. Material Science and Engineering. 7th ed. New York: Techbooks/GTS, 2007. p. 975.

[3] ČSN EN ISO 4957. Nástrojové oceli. Praha: Úřad pro technickou normalizaci, metrologii a státní zkušebnictví, 2003. p. 15.

[4] TOTTEN, G.E. Steel Heat Treatment. 2nd ed. New York: CRC Press, 2007. p. 691.

[5] DAVIS, J. R. Tool Materials. 1st ed. Materials Park: ASM International, 1995. p. 501.

[6] TOTTEN, G.E., Lin, X. and FUNATANI, K. Handbook of Mechanical Alloy Design. 1st ed. New York: M. Dekker, 2004. p. 164.

[7] FREMUNT, P., KREJČíK, J. and PODRÁBSKÝ, T. Nástrojové oceli. 1st ed. Brno: Dům techniky, 1994. p. 229.

[8] ČSN EN ISO 6507-1. Kovové materiály - tvrdost, test podle Vickerse-Část 1: Zkušební metoda. Prague: Úřad pro technickou normalizaci, metrologie a státní zkušebnu. 2018. p. 32.

[9] MURAKAMI, Y., KODAMA. S. and KONUMA, S. Quantitative evaluation of effects of non-metallic inclusions on fatigue strength of high strength steels. I: Basic fatigue mechanism and evaluation of correlation between the fatigue fracture stress and the size and location of non-metallic inclusions. International Journal of Fatigue. 1989. vol. 11, no. 5, pp. 291-298.

[10] YAN, M.F., WANG, Y.X. and CHEN, X.T. Laser quenching of plasma nitrided 30CrMnSiA steel. Materials and Design. 2014. vol. 58, pp. 154-160.

[11] JAGIELSKA-WIADEREK, K. Depth characteristics of glow-discharge nitrided layer produced on AISI 4140 steel. Archives of Metallurgy and Materials. 2010. vol. 55, no. 2, pp. 515-519.

[12] NASCIMENTO, F. C., FOERSTER, C.E., SILVA, S.L.R. LEPIENSKI, C.M., SIQUEIRA, C.J.M and ALVES, C. Jr. A comparative study of mechanical and tribological properties of AISI-304 and AISI-316 submitted to glow discharge nitriding. Materials Research. 2009. vol. 12, no. 2, pp. 173-180.

[13] QINGBIN, L. and HONG, L. Experimental study of the laser quenching of 40CrNiMoA steel. Journal of Materials Processing Technology. 1999. vol. 88, no. 1-3, pp. 77-82.

[14] NATH, A.K. and SARKAR, S. Laser Transformation Hardening of Steel. Advances in Laser Materials Processing. 2018. pp. 257-298.

[15] SMITH, E.H. Mechanical Engineer's Reference Book. 12th ed. Oxford: Butterworth-Hanemann, 1994. p. 1190. 